\title{
Pharmacokinetic characteristics and anticancer effects of 5-Fluorouracil loaded nanoparticles $\mathrm{Su} \mathrm{Li}^{* \dagger 1}$, Anxun Wang ${ }^{\dagger 2}$, Wenqi Jiang ${ }^{1}$ and Zhongzhen Guan ${ }^{1}$
}

Address: ${ }^{1}$ Department of Medicine, Tumor Hospital, Sun Yat-sen University, Guangzhou, China and ${ }^{2}$ Department of Oral and Maxillofacial Surgery, First Affiliated Hospital, Sun Yat-sen University, Guangzhou, China

Email: Su Li* - lisusu@tom.com; Anxun Wang - anxunwang@yahoo.com; Wenqi Jiang -wqjiang@yahoo.com; Zhongzhen Guan - zzguan@21cn.com

* Corresponding author †Equal contributors

Published: 15 April 2008

BMC Cancer 2008, 8:103 doi:10.1 186/147|-2407-8-103
Received: 9 August 2007

Accepted: 15 April 2008

This article is available from: http://www.biomedcentral.com/I47/-2407/8//03

(C) $2008 \mathrm{Li}$ et al; licensee BioMed Central Ltd.

This is an Open Access article distributed under the terms of the Creative Commons Attribution License (http://creativecommons.org/licenses/by/2.0), which permits unrestricted use, distribution, and reproduction in any medium, provided the original work is properly cited.

\begin{abstract}
Background: It is expected that prolonged circulation of anticancer drugs will increase their anticancer activity while decreasing their toxic side effects. The purpose of this study was to prepare 5-fluorouracil (5-FU) loaded block copolymers, with poly( $\gamma$-benzyl-L-glutamate) (PBLG) as the hydrophobic block and poly(ethylene glycol) (PEG) as the hydrophilic block, and then examine the 5-FU release characteristics, pharmacokinetics, and anticancer effects of this novel compound.

Methods: 5-FU loaded PEG-PBLG (5-FU/PEG-PBLG) nanoparticles were prepared by dialysis and then scanning electron microscopy (SEM) and transmission electron microscopy (TEM) were used to observe the shape and size of the nanoparticles, and ultraviolet spectrophotometry was used to evaluate the 5-FU in vitro release characteristics. The pharmacokinetic parameters of 5-FU/PEGPBLG nanoparticles in rabbit plasma were determined by measuring the 5-FUby high-performance liquid chromatography (HPLC). To study in vivo effects, LoVo cells (human colon cancer cell line) or Tca8II 3 cells (human oral squamous cell carcinoma cell line) were implanted in BALB/c nude mice that were subsequently treated with 5-FU or 5-FU/PEG-PBLG nanospheres.
\end{abstract}

Results: 5-FU/PEG-PBLG nanoparticles had a core-shell spherical structure with a diameter of 200 $\mathrm{nm}$ and a shell thickness of $30 \mathrm{~nm}$. The drug loading capacity was $27.1 \%$ and the drug encapsulation was $61.5 \%$. Compared with 5-FU, 5-FU/PEG-PBLG nanoparticles had a longer elimination half-life $\left(\mathrm{t}_{1 / 2}, 33.3 \mathrm{~h}\right.$ vs. $5 \mathrm{~min}$ ), lower peak concentration (C, $4563.5 \mu \mathrm{g} / \mathrm{L}$ vs. $\left.17047.3 \mu \mathrm{g} / \mathrm{L}\right)$, and greater distribution volume $\left(\mathrm{V}_{\mathrm{D}}, 0.1 \mathrm{I} 4 \mathrm{~L}\right.$ vs. $\left.0.069 \mathrm{~L}\right)$. Compared with a blank control, LoVo cell xenografts and Tca8I I 3 cell xenografts treated with 5-FU or 5-FU/PEG-PBLG nanoparticles grew slower and had prolonged tumor doubling times. 5-FU/PEG-PBLG nanoparticles showed greater inhibition of tumor growth than 5-FU $(p<0.01)$. In the PEG-PBLG nanoparticle control group, there was no tumor inhibition $(p>0.05)$.

Conclusion: In our model system, 5-FU/PEG-PBLG nanoparticles changed the pharmacokinetic behavior of 5-FU, thus increasing its anticancer activity. 5-Fluorouracil loaded nanoparticles have potential as a novel anticancer drug that may have useful clinical applications. 


\section{Background}

A large body of cancer research has been devoted to the development of targeted anti-neoplastic drugs that are selectively taken up by tumor tissues. Toward this end, researchers have recently developed anti-cancer drugs that are incorporated into polymeric micelles, surface-modified particles, liposomes, or nanoparticles [1-4]. However, there are problems with this general approach, including limited biodistribution, toxic side effects, rapid clearance by the reticuloendothelial system (RES), and limited distribution in the circulation.

Hydrophilic-hydrophobic diblock copolymers have great potential as vehicles for the delivery of anticancer drugs [5-9]. A hydrophobic block forms the inner core, which acts as a drug reservoir, and a hydrophilic block forms the hydrated outer shell, which impedes uptake by the RES $[10,11]$. The advantages of these copolymers includes solubilization of hydrophobic drugs, sustained release and selective targeting of drugs, and reduced drug interaction with the RES [10,11]. Nanoparticles prepared from poly( $\gamma$-benzyl-L-glutamate) (PBLG) and poly(ethylene glycol) (PEG) are a hydrophilic-hydrophobic diblock copolymer that have all of these characteristics [5-9]. PBLG, the hydrophobic moiety, is biodegradable and acts as a drug incorporation site [12]. PEG, the hydrophilic moiety, is a non-toxic, non-immunogenic hydrophilic polymer that prevents interactions with cells and proteins [13].

5-Fluorouracil (5-FU), a pyrimidine analogue that interferes with thymidylate synthesis, has a broad spectrum of activity against solid tumors. However, 5-FU has limitations that include a short biological half-life due to rapid metabolism, incomplete and non-uniform oral absorption due to metabolism by dihydropyrimidine dehydrogenase [14-17], toxic side effects on bone marrow and the gastrointestinal tract, and non-selective action against healthy cells [18].

In order to prolong the circulation time of 5-FU and increase its efficacy, numerous researchers have attempted to modify its delivery by use of polymer conjugates or by incorporation of 5-FU into particulate carriers [19-23]. The ultimate aim of these strategies is to reduce 5-FU associated side effects and thereby improve its therapeutic index [19-23]. In this study, we used a diafiltration method to prepare 5-FU-loaded PEG-PBLG (5-FU/PEGPBLG) nanoparticles and evaluate their physical characteristics, in vitro release behavior, and anti-tumor activity.

\section{Methods}

\section{Preparation of PEG-PBLG}

PEG-PBLG block copolymers (MW, $\left.1.12 \times 10^{4}\right)$ were prepared by polymerization of $\gamma$-benzyl-L-glutamate $\mathrm{N}$-car- boxyanhydride ( $\gamma$-BLG NCA) initiated with mono amineterminated PEG in a methylene dichloride solution, as described previously [24]. Briefly, we prepared the monoamino-terminated poly(ethylene glycol) (MeOPEG- $\mathrm{NH}_{2}$ ) by the use of toluene sulfonate esterification with $\mathrm{MeO}-\mathrm{PEG}-\mathrm{OH}$. The production rate of this process was $51.9 \%$ and the transformation rate was $68.2 \%$. The $\gamma-$ benzyl-L-glutamate was obtained by reaction of glutamic acid with benzyl alcohol at $120^{\circ} \mathrm{C}$ for $5 \mathrm{~h}$ under $60 \%$ sulfuric acid (activator), and then reacted with triphosgene to obtain the monomer of $\gamma$-benzyl-L-glutamate $\mathrm{N}$-carboxyl anhydride (BLG-NCA). The process production rate was $53.2 \%$. The amphiphilic block copolymer was the prepared by anionic polymerization of BLG-NCA initiated by MeO-PEG- $\mathrm{NH}_{2}$ with a 50/1 molar ratio of monomer/initiator. The resulting molecular weight was $1.12 \times 10^{4}$. IR and $1 \mathrm{H}-\mathrm{NMR}$ demonstrated that $\mathrm{MeO}-\mathrm{PEG}-\mathrm{NH}_{2}$ was polymerized with BLG-NCA to form PEG-PBLG.

\section{Drug and Chemicals}

5-FU was purchased from Sigma (USA). Other chemicals were of laboratory grade purity.

\section{Cell Culture}

Human colon cancer cells (LoVo cell line) and human oral squamous carcinoma cells (Tca8113 cell line) were grown in RPMI 1640 medium (GIBCO) with 10\% fetal calf serum (GIBCO), 100 units $/ \mathrm{ml}$ penicillin $\mathrm{G}$, and 100 $\mu \mathrm{g} / \mathrm{ml}$ streptomycin at $37^{\circ} \mathrm{C}$ in $5 \% \mathrm{CO}_{2}$.

\section{Animals}

New Zealand rabbits (2-3 kg) and BALB/c nude mice (68 weeks old, 20-30 g) were purchased from the animal center at Sun Yat-sen University (Guangzhou, China). All animal experiments were performed with permission of the Animal Ethical Commission of Sun Yat-sen University.

\section{Preparation and identification of 5-FU/PEG-PBLG nanoparticles}

5-FU/PEG-PBLG nanoparticles were prepared by a diafiltration method. Briefly, we dissolved PEG-PBLG diblock copolymers and 5-FU $(1: 1 \mathrm{w} / \mathrm{w})$ in dimethylformamide (DMF) and dialyzed the solution (with a molecular weight cut-off of $3500 \mathrm{~g} / \mathrm{mol}$; Spectrum Medical Industries, Inc., Houston, TX) in double-distilled water for $24 \mathrm{~h}$. The solution inside the dialysis bags was collected and then centrifuged (2000 $\mathrm{rpm} / \mathrm{min} ; 10 \mathrm{~min}$ ). The supernatant (nanoparticles) was filtered with a $0.45 \mu \mathrm{m}$ filter. The samples were then freeze-dried for subsequent use. A 640 UV spectrophotometer (Bechman) was used to identify the 5-FU/PEG-PBLG nanoparticles by scanning from 200 $\mathrm{nm}$ to $400 \mathrm{~nm}$. 


\section{Morphology of PEG-PBLG nanoparticles}

A scanning electron microscope (HITACH-600, Japan) and a transmission electron microscope (PHILIPS, Holland) were used to examine particle morphology. For SEM, PEG-PBLG samples were filtered with a $0.45 \mu \mathrm{m}$ sieve and dropped onto a slide. The prepared samples were dried at room temperature for several days and then gilded. The final concentration of the gilded samples was $0.2 \mathrm{mg} / \mathrm{ml}$. For TEM, one drop of the PEG-PBLG sample was added to a copper supported mesh membrane and the excess solution removed with filter paper. Then, $1 \%$ phosphotungstic acid was added to the mesh membrane. Excess solution was removed after 1 minute and the sample dried at room temperature. The concentration of prepared sample was $0.2 \mathrm{mg} / \mathrm{ml}$.

Loading capacity, drug encapsulation, and in vitro release 5-FU/PEG-PBLG nanoparticles were placed into dialysis bags and the bags were introduced into a DMF solution. After stirred at $37^{\circ} \mathrm{C}$ for $3 \mathrm{~h}$ dialysed sample was determined for drug concentration by measuring absorbance at $269 \mathrm{~nm}$. The drug loading capacity and drug encapsulation were calculated by the following formulas:

$$
\begin{gathered}
\text { Drug loading capacity }=M_{5-\mathrm{FU}} / \mathrm{M}_{5 \text {-FU/PEG-PBLG }} \\
\text { Drug encapsulation }=\mathrm{M}_{5 \text {-FU }} / \mathrm{M}_{\text {drug devoted }}
\end{gathered}
$$

where $M_{5-\mathrm{FU}}$ was the drug content detected in solution $\left[\mathrm{M}_{5-\mathrm{FU}}=\mathrm{D}_{5-\mathrm{FU}} \times \mathrm{V}, \mathrm{D}_{5-\mathrm{FU}}=\left(\mathrm{A}_{\text {sample }} / \mathrm{A}_{\text {standard }}\right) \times \mathrm{D}_{\text {standard }^{\prime}} \mathrm{D}\right.$ : concentration, $\mathrm{V}$ : volume]; $\mathrm{M}_{5 \text {-FU/PEG-PBLG }}$ was quantity of 5-FU/PEG-PBLG nanoparticles detected in solution; and $\mathrm{M}_{\text {drug devoted }}$ was the initial quantity of 5-FU.

For in vitro release studies, 5-FU/PEG-PBLG nanoparticles were placed into dialysis bags and the bags were introduced into PBS at $\mathrm{pH} 6.86$ or $\mathrm{pH} 9.18$. The medium was stirred at $94 \pm 4$ beats $/ \mathrm{min}$ at $37^{\circ} \mathrm{C}$. The medium was replaced with fresh $\mathrm{PBS}$ at variable periods of time up to $96 \mathrm{~h}$. We determined the concentration of 5-FU that was released into the PBS by measuring the absorbance at 269 nm.

\section{Pharmacokinetic studies of 5-FU/PEG-PBLG nanoparticles in rabbit plasma}

A single dose of 5-FU or 5-FU/PEG-PBLG nanoparticles (30 mg/kg) was administered to rabbits. Blood samples were collected from rabbit veins at designated times after intravenous administration. 5-FU was extracted from plasma by mixing rabbit plasma with ethyl acetate and isopropyl alcohol $(85 / 15, \mathrm{v} / \mathrm{v})$. The samples were then dried with $\mathrm{N}_{2}$ at $37^{\circ} \mathrm{C}$ and the dehydrated samples were dissolved in $400 \mu \mathrm{l}$ of mobile phase dilutent for subsequent HPLC.
The concentration of released 5-FU was measured using reversed-phase HPLC (HP1100 Liquid Chromatogragh, Agilent). A Hypersil C18 (5 $\mu \mathrm{m}$, ID $4.6 \mathrm{~mm} \times 300 \mathrm{~mm}$ ) analytical column was used with a mobile phase of 0.01 $\mathrm{mol} / \mathrm{L}$ phosphate buffer ( $\mathrm{pH} 3.0$ ) and an elution rate of $1.0 \mathrm{ml} / \mathrm{min}$ at room temperature. Absorbance at $269 \mathrm{~nm}$ was monitored and pharmacokinetic parameters were determined from the absorbance-time curves. This method provided complete separation with a corresponding retention time of 7.0 minutes for 5-FU. The standard calibration curve of 5-FU absorbance with concentration was $y=3.47 x+0.24(\gamma>0.9998)$. The lower limit of determination was $5 \mu \mathrm{g} / \mathrm{L}$.

\section{In vivo tumor inhibition effect of 5-FU loaded nanoparticles}

LoVo cells were subcutaneously implanted in the right flank of BALB/C nude mice. Mice were assigned to one of 4 groups $(\mathrm{n}=8)$ after xenografts were about $5 \mathrm{~mm}$ in diameter: 1) control group (PBS), 2) PEG-PBLG group, 3) 5-FU group, 4) 5-FU/PEG-PBLG nanoparticle (3 mg/kg) group. For groups 3 and 4, intraperitoneal injections were administered daily for 7 days. For groups 1 and 2, intraperitoneal injections of the same volume of PBS or PEGPBLG were administered on the same schedule. The mice were sacrificed on day 21 and tumor size was measured (length and width) with a caliperevery 3 days. Tumor parameters were calculated on day 21 by the following formulas: Tumor volume $=\left(1 / 2 \times\right.$ length $\times$ width $\left.^{2}\right)$; Tumor doubling time $=(\ln 2 / \mathrm{K}$ where $\mathrm{K}=$ growth rate $)$; Inhibition rate at day $21=(1$ - volume change of experimental group/volume change of control group) $\times 100 \%$.

For the mice with implanted Tca8113 cells, 5-FU or 5-FU/ PEG-PBLG (3 mg/kg) was injected intraperitoneally every 2 days for 16 days. Mice were sacrificed on day 34 .

\section{Statistical analysis}

All experiments were performed in triplicate and data are presented as mean \pm SD. The tumor growth inhibitory effect of drugs was analyzed using one-way analysis of variance. $\mathrm{P}<0.05$ was considered as statistically significant.

\section{Results and Discussion \\ Characteristics of 5-FUIPEG-PBLG nanoparticles}

Drug-loaded nanoparticles have a diameter ranging from $10 \mathrm{~nm}$ to $500 \mathrm{~nm}$ and incorporate a drug by conjugation, physical entrapment, absorption, or by other mechanisms. Nanoparticles can enhance the solubilization of a hydrophobic drug, protect drug activity, increase drug stability, improve the drug's therapeutic index, and decrease adverse side effects [2-9]. Drug-loaded nanoparticles are widely used for anticancer drugs because of their enhanced targeting properties [2-9,25]. Previously, researchers have used copolymers of PEG and PBLG, a 
biocompatible and biodegradable macromolecular material, as the nanoparticle carrier for a drug [5-9]. In this study, we prepared 5-FU/PBLG-PEG nanoparticles by a diafiltration method. Analysis by UV spectrophotometry (Figure 1) showed that a solution of 5-FU, or a simple mixture of 5-FU and PBLG-PEG nanoparticles, had high absorbance at $269 \mathrm{~nm}$. However, the absorbance of 5-FU/ PEG-PBLG nanoparticles at $269 \mathrm{~nm}$ had greatly decreased. This indicates that 5-FU can be loaded into PEG-PBLG nanoparticles by diafiltration. Based on the decrease in absorbance at $269 \mathrm{~nm}$, we estimate the drug loading capacity as $27.1 \%$ and the drug encapsulation as $61.5 \%$.

Experiments to determine drug release and pharmacokinetics were performed to demonstrate the reliability of the aforementioned observation. It's also of note that the drug loading capacity in our study was higher than the $10 \%$ achieved by Nagaich et al. [19] who prepared 5-FU loaded PEG-polysaccharide nanoparticles. Whether the difference is due to the PBLG component, which has a steel-like structure and forms a hydrophobic core, remains to be determined [26-28].
Like many other polymeric nanoparticles [5-9], the morphology of our 5-FU/PEG-PBLG nanoparticles is spherical or elliptical, with a core-shell structure, and a smooth surface (Figure 2). The hydrophobic PBLG central core is a non-gilt grizzly area, about $200 \mathrm{~nm}$ in diameter, and the PEG hydrophilic shell is a gilt white area, approximately $30 \mathrm{~nm}$ in thickness (Figure 2A). A representative TEM scan of the 5-FU/PEG-PBLG nanoparticle is shown in Figure 2B. Previous research has shown that nanoparticles are not easily phagocytized when the thickness of the PEG layer is $10 \mathrm{~nm}$ for every $100 \mathrm{~nm}$ thickness of the micelles. This indicates that the RES should not take up the 5-FU/ PEG-PBLG nanoparticles examined in this study.

\section{In vitro release of 5-FU loaded nanoparticles}

Nanoparticle release occurs by 2 methods: "burst release" and "sustained release" [29-32]. Burst release is the rapid release of a drug from the surface of nanoparticles or diffusion from the polymer matrix. This allows the drug to rapidly reach an effective concentration in the circulation. Sustained release is the slow release of a drug that is entrapped within nanoparticles during nanoparticle bio-

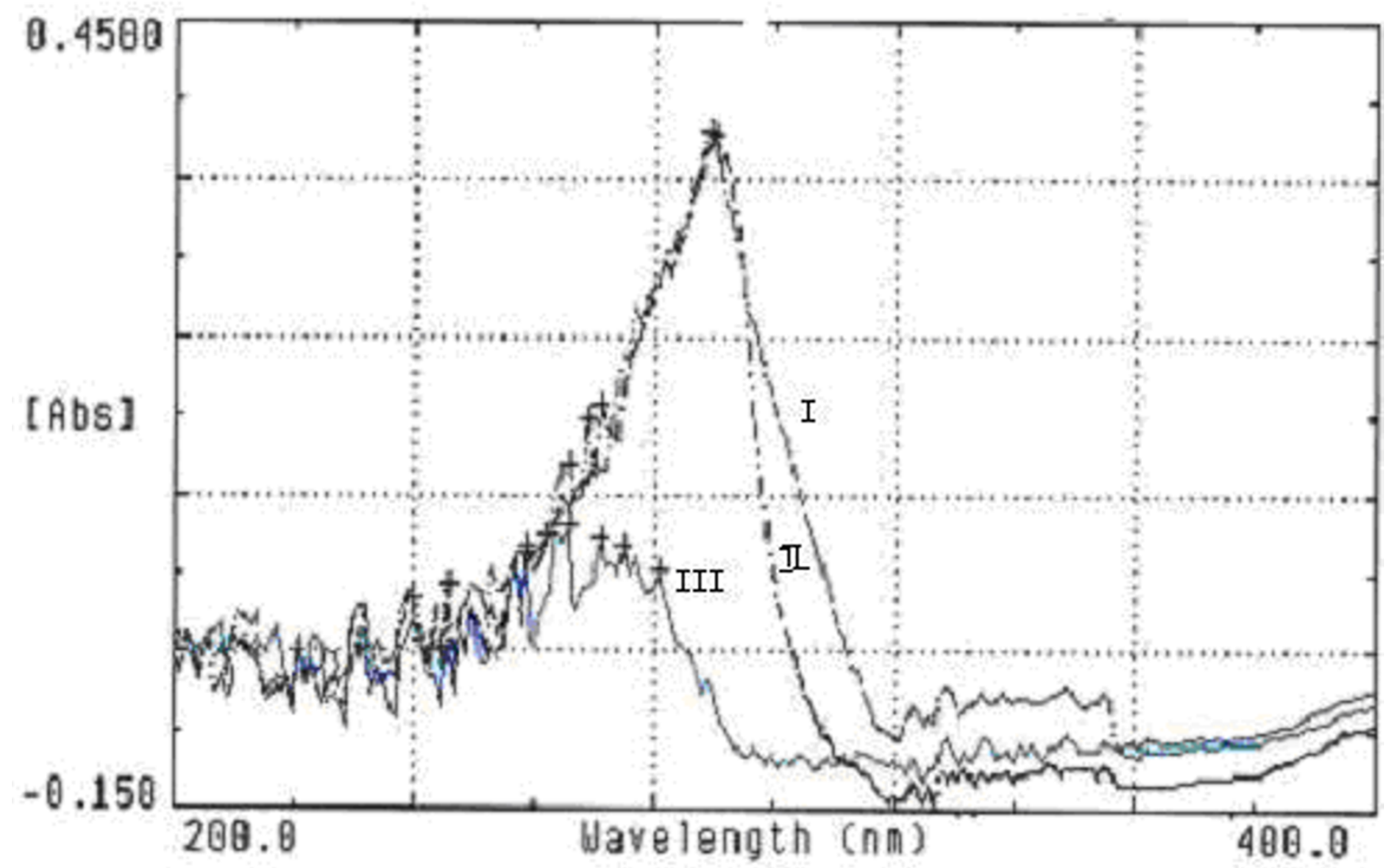

Figure I

UV spectra of 5-FU/PEG-PBLG nanoparticles. I: 5-FU; II: 5-FU + PEG-PBLG nanoparticles; III: 5-FU/PEG-PBLG nanoparticles. I and II had high absorbance at $269 \mathrm{~nm}$ while the absorbance of III was much lower at $269 \mathrm{~nm}$. 


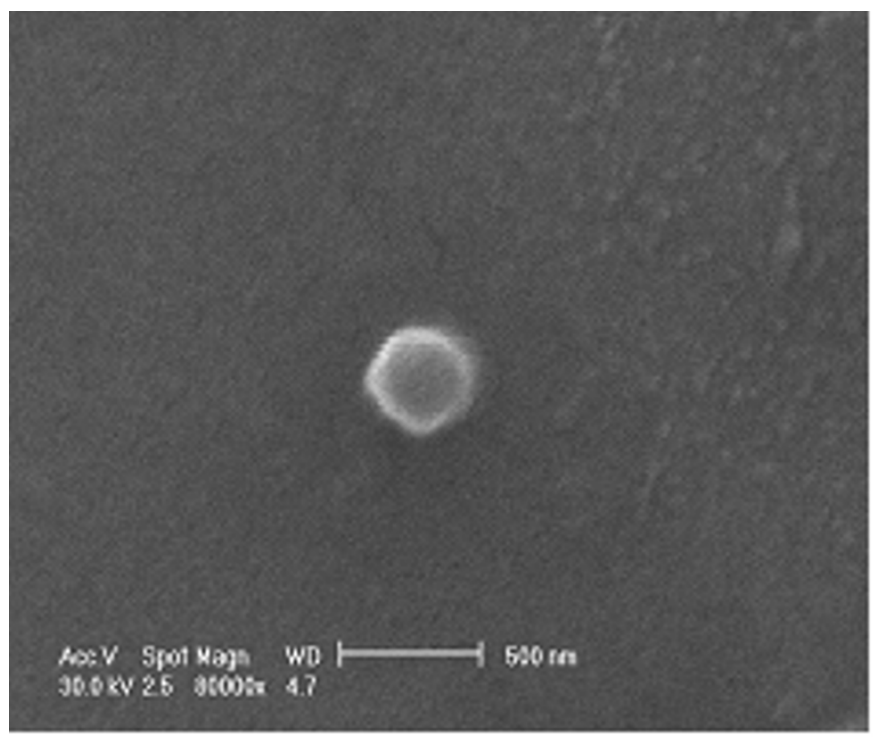

A

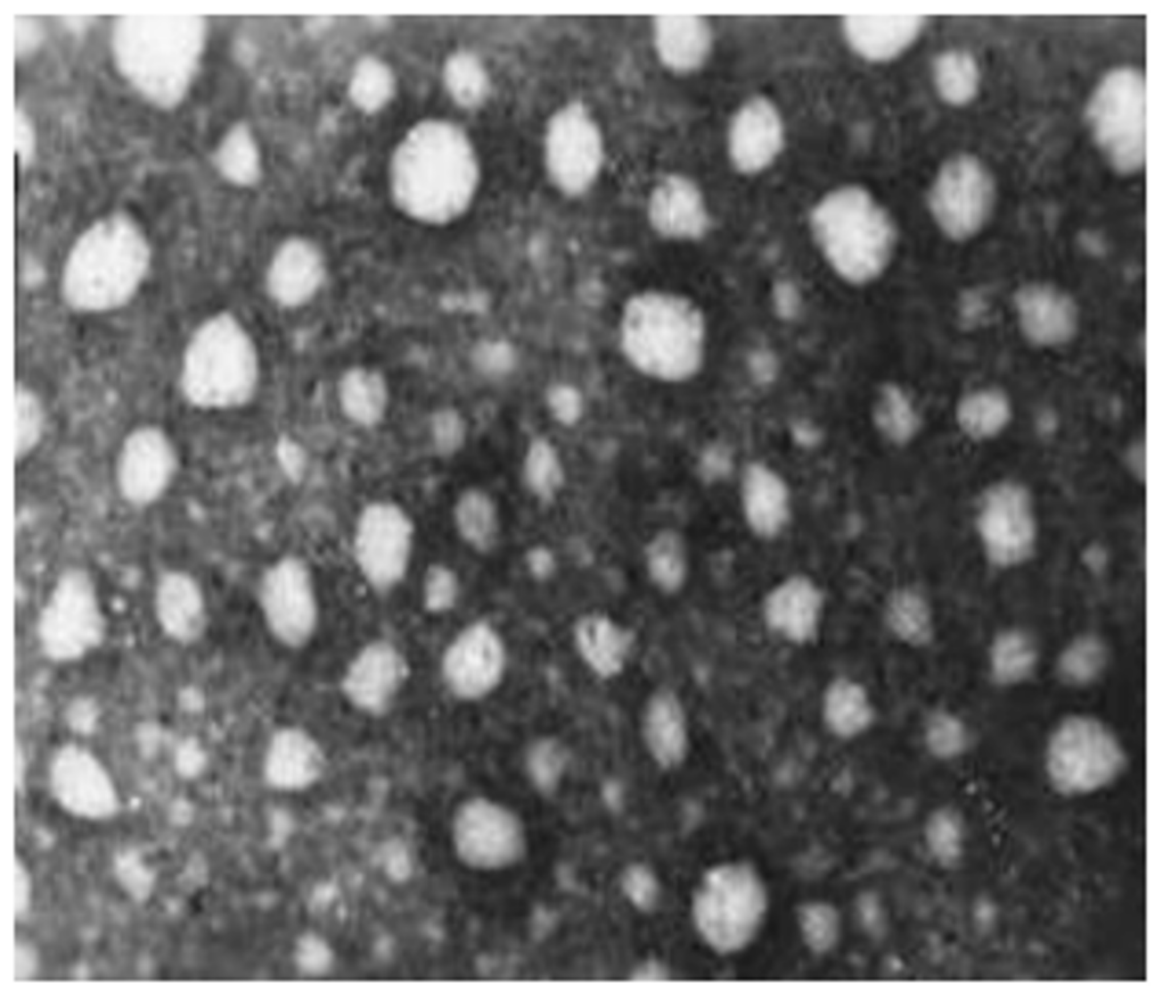

B

\section{Figure 2}

The core-shell structure of 5-FU/PEG-PBLG nanoparticles. (A) Morphology under SEM $(\times 80000)$. SEM showed 5-FU/PEG-PBLG nanoparticles have a core-shell structure, a spherical or elliptical shape, and a smooth surface. The hydrophobic central core is a non-gilt grizzly area, about $200 \mathrm{~nm}$ in diameter and the hydrophilic shell is a gilt white area, about $30 \mathrm{~nm}$ in thickness. (B) Morphology under TEM ( $\times$ 50000). TEM showed that nanomicelles were round or oval particles of uniform size with fuzzy edges. 
degradation. This allows the drug to stay at an effective concentration in the circulation over time. Figure 3 shows the in vitro 5-FU release profiles from PEG-PBLG nanoparticles at $\mathrm{pH} 6.86$ and $\mathrm{pH} 9.18$. This brackets the normal $\mathrm{pH}$ of human blood ( $\mathrm{pH} \sim 7.4$ ). The 5-FU release profiles are composed of burst release and sustained release [33]. The burst release, which resulted in the release of $\sim 30 \%$ of the 5-FU, occurred from 0 to $2 \mathrm{~h}$. The sustained release occurred from 2 to $96 \mathrm{~h}$ and resulted in the release of $\sim 50 \%$ of the 5 -FU.

\section{Pharmacokinetics characteristic of 5-FU/PEG-PBLG nanoparticles in vivo}

Clinically, 5-FU can be administered by bolus injection, which primarily inhibits RNA synthesis, or by continuous infusion, which primarily inhibits DNA synthesis. Clinical response would be expected to be enhanced if both methods could be combined [16,17]. The half-life of 5-FU in vivo is only 5 to $10 \mathrm{~min}$; thus, many studies have attempted to develop 5-FU preparations with a prolonged lifetime [21,32].
To study the in vivo characteristics of the 5-FU/PEG-PBLG nanoparticles, we administered 5-FU or 5-FU/PEG-PBLG nanoparticles to rabbits at a single dose of $30 \mathrm{mg} / \mathrm{kg}$. The absolute recovery and relative recovery of 5-FU were 73.5 to $82.6 \%$ and 98.6 to $100.8 \%$, respectively. The intra- and inter-day RSD (relative standard deviation) was less than $10 \%$, justifying this method for study of 5-FU pharmacokinetics in rabbits. As Figure 4 shows, 5-FU alone followed a one-compartment model, but 5-FU/PEG-PBLG nanoparticles followed a multi-compartment model with a burst release followed by a sustained release. Compared with 5-FU, 5-FU/PEG-PBLG nanoparticles have a greater elimination half-life $\left(t_{1 / 2}\right)$, lower peak concentration $\left(\mathrm{C}_{\max }\right)$, greater distribution volume $\left(\mathrm{T}_{\max }\right)$, and slightly lower area under the curve (AUC) (Table 1). This indicates that when 5-FU is loaded into nanoparticles, the 5-FU has sustained-release, prolonged half-life, and increased tissue appetency. It is noteworthy that the pharmacokinetic characteristics of our 5-FU loaded PEG/PBLG nanoparticles are similar to the 5-FU loaded PEG-polysaccharide nanoparticles of Nagaich et al. [19].

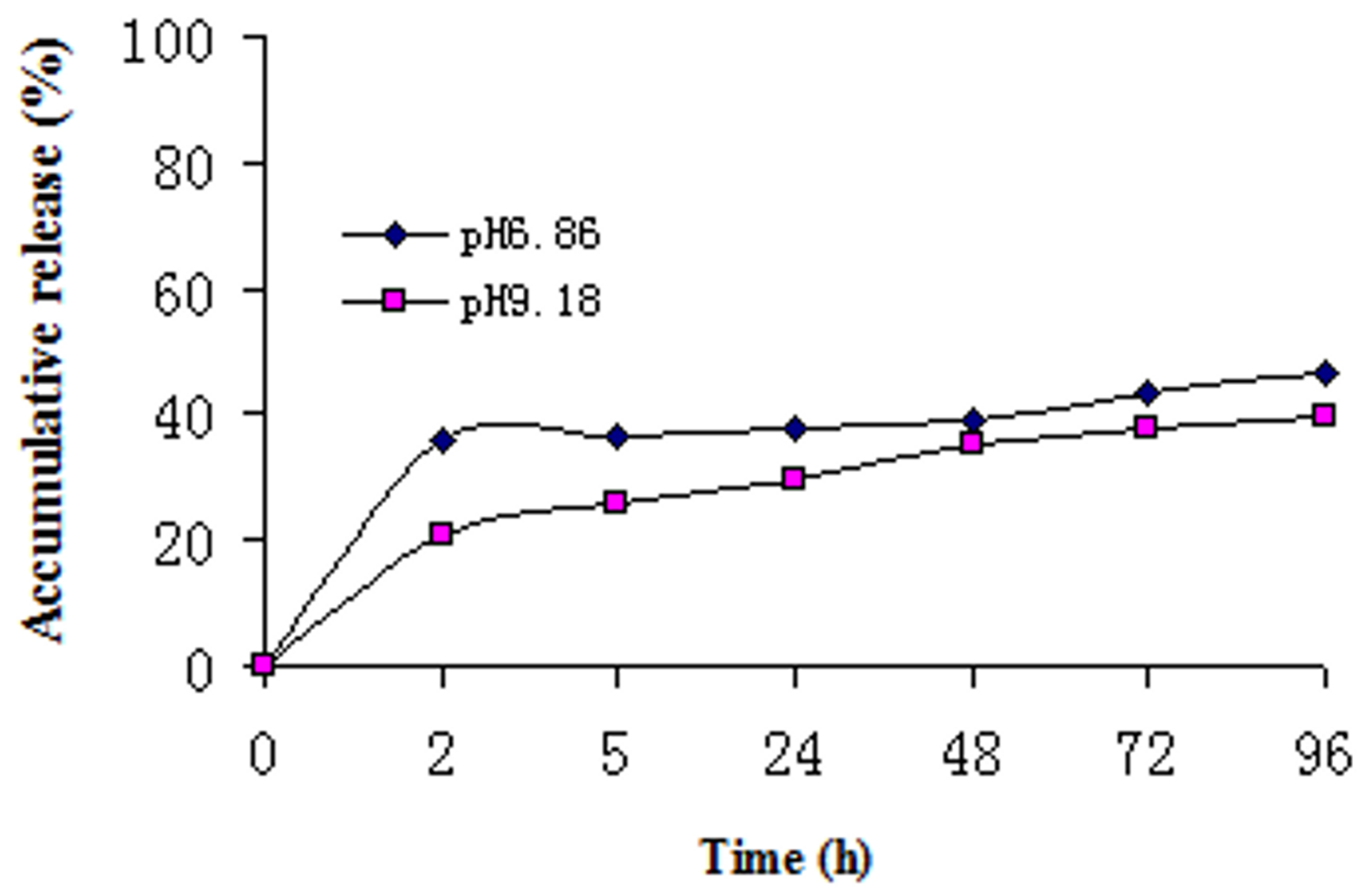

Figure 3

In vitro release of 5-FU from PEG-PBLG nanoparticles at pH 6.86 and pH 9.I8. 


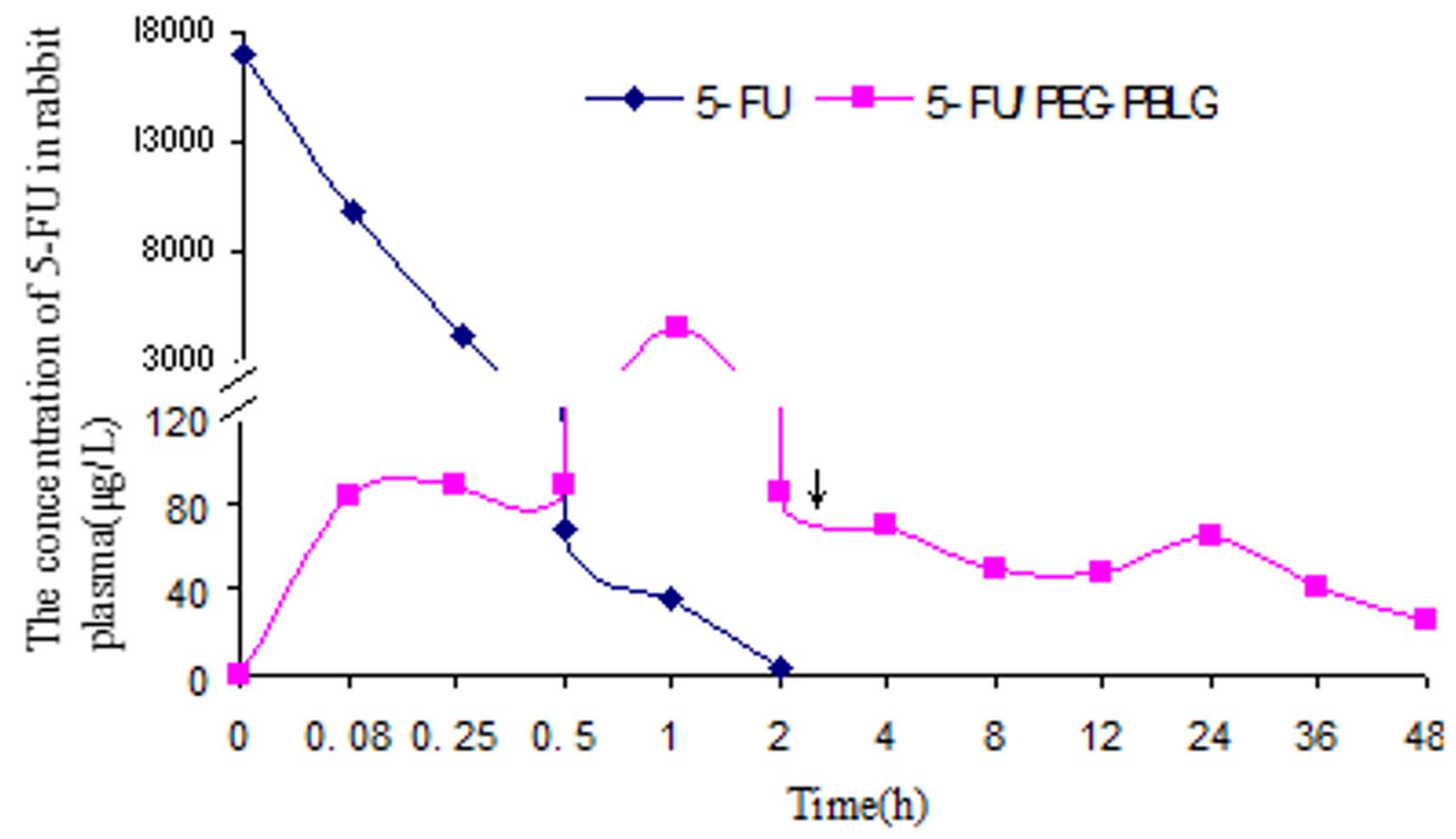

\section{Figure 4}

Mean plasma concentration of 5-FU following a single i.v. administration of 5-FU or 5-FU/PEG-PBLG nanoparticles at $30 \mathrm{mg} / \mathrm{kg}$. The arrow depicts sustained release.

\section{Anticancer effect of 5-FU loaded nanoparticles in vivo} 5 -FU is clinically effective against human colorectal cancer and oral squamous cell carcinoma [14]. Figures 5A and 5B show that LoVo cell xenografts (colorectal cancer) and Tca8113 cell xenografts (oral squamous carcinoma) grew rapidly in blank and in the PEG-PBLG control groups. However, 5-FU and 5-FU/PEG-PBLG nanoparticles significantly inhibited tumor growth. Tumor doubling times and inhibition rates are presented in Table 2. There were no differences between the 2 control groups ( $p>0.05$ ), but there were significant differences between the 2 treated groups $(\mathrm{p}<0.01)$. We observed no significant toxicity in any group. The more effective anticancer effect of 5-FU/PEG-PBLG nanoparticles (Figure 5, Table 2) may be due to: 1) the sustained-release, prolonged half-life, and increased apparent volume of distribution of 5-FU/PEG-
PBLG nanoparticles and/or 2) the neovascularization and higher permeability of blood vessels present in tumor cells, making it easier for nanoparticles to enter tumor cells and thereby increase the anticancer effect of 5-FU.

\section{Conclusion}

In this study, we prepared 5-FU loaded PEG-PBLG nanoparticles (5-FU/PEG-PBLG) which exhibited favorable pharmacokinetic characteristics, including sustained drug release, prolonged drug half-life, and increased tissue appetency. In vivo, 5-FU/PEG-PBLG nanoparticles had good anti-tumor activity against colon cancer xenografts and oral squamous cell carcinoma xenografts. Taken together, our results indicate that a PEG-PBLG nanoparticle delivery system for 5-FU may be able to effectively

Table I: In vivo pharmacokinetic parameters of 5-FU and 5-FU/PEG-PBLG nanoparticles

\begin{tabular}{llllll}
\hline & $\mathbf{t}_{\mathbf{1} / 2}(\mathbf{h})$ & $\mathbf{C}_{\max }(\mu \mathrm{g} / \mathrm{L})$ & $\mathbf{T}_{\max }(\mathbf{h})$ & $\mathbf{V}_{\mathbf{d}}(\mathbf{L})$ & $\mathbf{A U C}(\mu \mathbf{g} \cdot \mathbf{h} / \mathbf{L})$ \\
\hline 5-FU & 0.088 & 17047.3 & 0 & 0.069 & 6263.7 \\
5-FU/PEG-PBLG & 33.3 & 4563.5 & 1.25 & 0.114 & 5794.7 \\
\hline
\end{tabular}

$t_{1 / 2}$, elimination half-life; $C_{\max }$, peak concentration; $T_{\max }$, peak time; $A U C$, area under the concentration-time curve; $V_{d}$, distribution volume. 


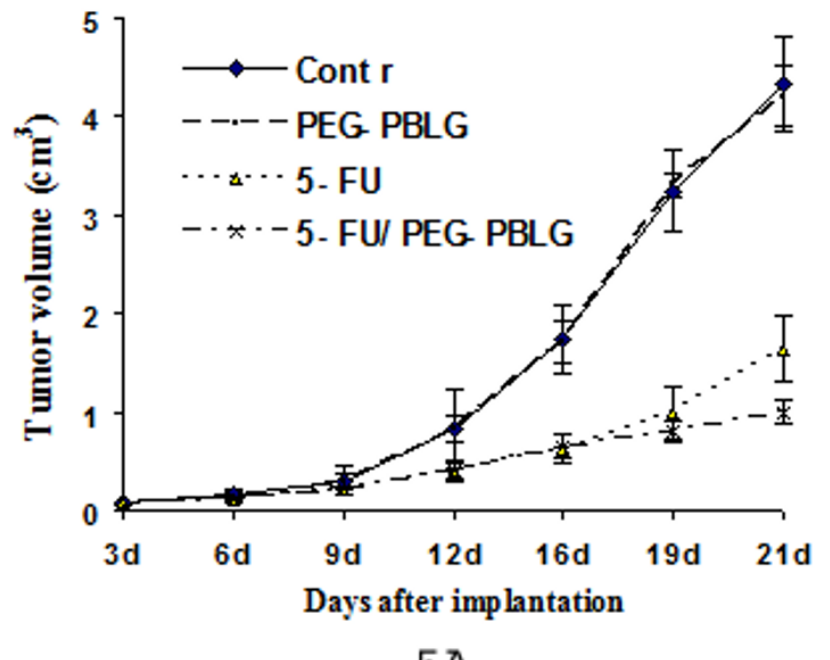

$5 \mathrm{~A}$

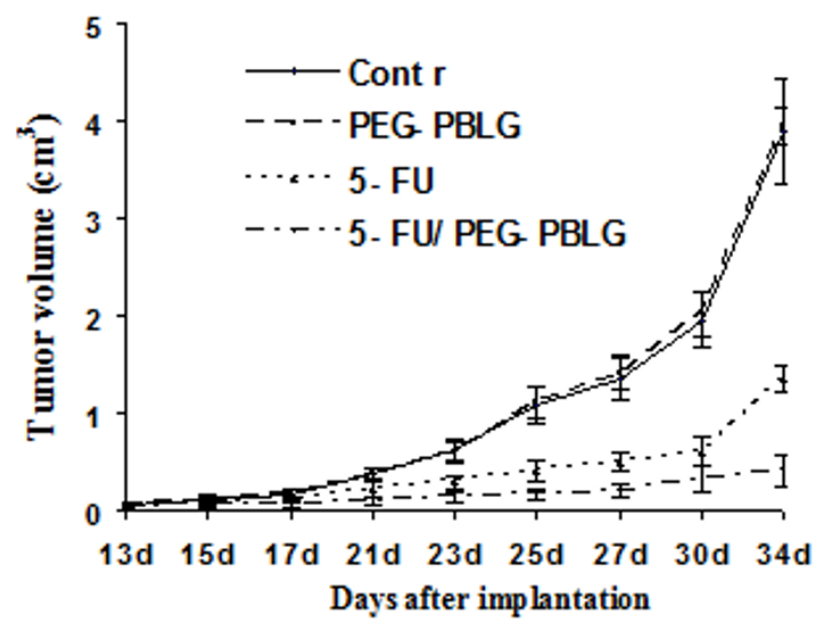

$5 B$

\section{Figure 5}

Tumor growth of LoVo cell xenografts (A) and Tca8 I I 3 cell xenografts (B) after treatment with 5-FU or 5-FU/ PEG-PBLG nanoparticles.

reduce adverse side effects of 5-FU therapy and improve the therapeutic index of 5-FU.

\section{List of abbreviations}

5-FU, 5-fluorouracil; PBLG, poly( $\gamma$-benzyl L-glutamate); PEG, poly(ethylene glycol); SEM, scanning electron microscopy; HPLC, high-performance liquid chromatography; RES, reticuloendothelial system, DMF, N,Ndimethylformamide; $\mathrm{t}_{1 / 2}$, elimination half-life; $\mathrm{C}_{\text {max }^{\prime}}$ peak concentration; $\mathrm{T}_{\text {max }}$ peak time; $\mathrm{AUC}$, area under the concentration-time curve; $\mathrm{V}_{\mathrm{D}^{\prime}}$ distribution volume; TDT, tumor doubling time; IR, inhibition rate; TV, tumor volume at day 21 for LoVo cell xenografts or day 34 for Tca 8113 cell xenografts.

\section{Competing interests}

The author(s) declare that they have no competing interests

Table 2: The anticancer effect of 5-FU/PEG-PBLG nanoparticles

\begin{tabular}{lcccccc}
\hline & \multicolumn{3}{c}{ LoVo cell xenografts } & \multicolumn{2}{c}{ Tca8 I I3 cell xenografts } \\
& TDT (d) & IR (\%) & TV(cm $\left.{ }^{3}\right)$ & TDT (d) & IR (\%) & TV(cm $\left.{ }^{3}\right)$ \\
\hline Blank control & 3.0 & 0 & $4.336 \pm 0.485$ & 3.5 & 0 & $3.888 \pm 0.547$ \\
PEG-PBLG & 2.9 & 0 & $4.206 \pm 0.308^{*}$ & 3.6 & 0 & $3.944 \pm 0.179 *$ \\
5-FU & 4.08 & $62.2 \%$ & $1.637 \pm 0.330^{\#}$ & 4.6 & $65.4 \%$ & $1.346 \pm 0.142^{\#}$ \\
5-FU/PEG-PBLG & 4.50 & $77.1 \%$ & $0.993 \pm 0.122^{\#}$ & 5.3 & $89.6 \%$ & $0.405 \pm 0.174 \# 3$
\end{tabular}

TDT, tumor doubling time; IR, inhibition rate; TV, tumor volume at day $2 \mathrm{I}$ for LoVo cell xenografts and at day 34 for Tca $81 \mathrm{I} 3$ cell xenografts. *compared with blank control, $\mathrm{p}>0.05$. \#compared with blank control, $\mathrm{p}<0.01$, §compared with 5-FU, $p<0.01$.

\section{Authors' contributions}

SL and AW were responsible for experimental design and completion of all laboratory work. WJ and ZG participated in the design and coordination of the work. SL and AW wrote the manuscript. All authors have read and approved the final manuscript. 


\section{Acknowledgements}

This study was supported by grant 021865 of the Natural Science Foundation of Guangdong Province and grant 5300802 of the Natural Science Foundation of Guangdong Province.

\section{References}

I. Mainardes RM, Silva LP: Drug delivery systems: past, present, and future. Curr Drug Targets 2004, 5(5):449-455.

2. Wang MD, Shin DM, Simons JW, Nie S: Nanotechnology for targeted cancer therapy. Expert Rev Anticancer Ther 2007, 7(6):833-837.

3. Seow WY, Xue JM, Yang YY: Targeted and intracellular delivery of paclitaxel using multi-functional polymeric micelles. Biomaterials 2007, 28(9): 1730-1740.

4. Zentner GM, Rathi R, Shih C, McRea JC, Seo MH, Oh H, Rhee BG, Mestecky J, Moldoveanu Z, Morgan M, Weitman S: Biodegradable block copolymers for delivery of proteins and water-insoluble drugs. J Control Release 200I, 72(I-3):203-2I5.

5. Jeong YI, Cheon JB, Kim SH, Nah JW, Lee YM, Sung YK, Akaike T, Cho CS: Clonazepam release from core-shell type nanoparticles in vitro. J Control Release 1998, 5 I(2-3): 169-178.

6. Jeong $\mathrm{YI}, \mathrm{Nah} \mathrm{JW}$, Lee HC, Kim SH, Cho CS: Adriamycin release from flower-type polymeric micelle based on star-block copolymer composed of poly (gamma-benzyl L-glutamate) as the hydrophobic part and poly(ethylene oxide) as the hydrophilic part. Int J Pharm 1999, I 88( I):49-58.

7. Oh I, Lee K, Kwon HY, Lee YB, Shin SC, Cho CS, Kim CK: Release of adriamycin from poly(gamma-benzyl-L-glutamate)/ poly(ethylene oxide) nanoparticles. Int J Pharm 1999, I8I(I): I07-II5.

8. Mandal D, Chatterjee U: Synthesis and spectroscopy of CdS nanoparticles in amphiphilic diblock copolymer micelles. J Chem Phys 2007, I 26(1 3): 134507.

9. Arimura $\mathrm{H}$, Ohya $\mathrm{Y}$, Ouchi T: Formation of core-shell type biodegradable polymeric micelles from amphiphilic poly(aspartic acid)-block-polylactide diblock copolymer. Biomacromolecules 2005, 6(2):720-725.

10. Jeong YI, Kang MK, Sun HS, Kang SS, Kim HW, Moon KS, Lee KJ, Kim $\mathrm{SH}$, Jung S: All-trans-retinoic acid release from core-shell type nanoparticles of poly(epsilon-caprolactone)/poly(ethylene glycol) diblock copolymer. Int J Pharm 2004, 273( I-2):95-107.

II. Dong AJ, Deng LD, Sun DX, Zhang YT, Jin JZ, Yuan YJ: Studies on paclitaxel-loaded nanoparticles of amphiphilic block copolymer. Yao Xue Xue Bao 2004, 39(2): 149-152.

12. Yoda R, Komatsuzaki S, Hayashi T: Surface properties and biocompatibility of A-B-A type block copolymer membranes consisting of poly(gamma-benzyl-L-glutamate) as the $A$ component and polyisoprene as the B component. Biomaterials 1995, 16(16): 1203-1209.

13. Jeong YI, Seo SJ, Park IK, Lee HC, Kang IC, Akaike T, Cho CS: Cellular recognition of paclitaxel-loaded polymeric nanoparticles composed of poly(gamma-benzyl L-glutamate) and poly(ethylene glycol) diblock copolymer endcapped with galactose moiety. Int J Pharm 2005, 296(I-2):15I-16I.

14. Diasio RB, Lu Z: Dihydropyrimidine dehydrogenase activity and fluorouracil chemotherapy. J Clin Oncol 1994, I 2(II):2239-2242.

15. Schilsky RL, Hohneker J, Ratain MJ, Janisch L, Smetzer L, Lucas VS, Khor SP, Diasio R, Von Hoff DD, Burris HA 3rd: Phase I clinical and pharmacologic study of eniluracil plus fluorouracil in patients with advanced cancer. I Clin Oncol 1998, 16(4): 1450-1457.

16. Gamelin EC, Danquechin-Dorval EM, Dumesnil YF, Maillart PJ, Goudier M], Burtin PC, Delva RG, Lortholary AH, Gesta PH, Larra FG: Relationship between 5-fluorouracil (5-FU) dose intensity and therapeutic response in patients with advanced colorectal cancer receiving infusional therapy containing 5-FU. Cancer 1996, 77(3):44|-45I.

17. Aranda E, Diaz-Rubio E, Cervantes A, Anton-Torres A, Carrato A, Massuti T, Tabernero JM, Sastre J, Tres A, Aparicio J, Lopez-Vega JM, Barneto I, Garcia-Conde J: Randomized trial comparing monthly low-dose leucovorin and fluorouracil bolus with weekly high-dose 48-hour continuous-infusion fluorouracil for advanced colorectal cancer: a Spanish Cooperative Group for Gastrointestinal Tumor Therapy (TTD) study. Ann Oncol 1998, 9(7):727-73I.

18. Shirasaka T, Yamamitsu S, Tsuji A, Terashima M, Hirata K: Conceptual changes in cancer chemotherapy--biochemical modulation of 5-FU. Gan To Kagaku Ryoho 2000, 27(6):832-845.

19. Nagaich S, Khopade AJ, Jain NK: Lipid grafts of egg-box complex: a new supramolecular biovector for 5-fluorouracil delivery. Pharm Acta Helv 1999, 73(5):227-236.

20. Simeonova M, Velichkova R, Ivanova G, Enchev V, Abrahams I: Study on the role of 5 -fluorouracil in the polymerization of butylcyanoacrylate during the formation of nanoparticles. J Drug Target 2004, I 2(1):49-56.

21. Simeonova M, Velichkova R, Ivanova G, Enchev V, Abrahams I: Poly(butylcyanoacrylate) nanoparticles for topical delivery of 5-fluorouracil. Int J Pharm 2003, 263(I-2): I33-I 40.

22. Sastre RL, Olmo R, Teijon C, Muniz E, Teijon JM, Blanco MD: 5Fluorouracil plasma levels and biodegradation of subcutaneously injected drug-loaded microspheres prepared by spraydrying poly(D,L-lactide) and poly(D,L-lactide-co-glycolide) polymers. Int J Pharm 2007, 338(I-2): $180-190$.

23. Marchal JA, Boulaiz $H$, Rodriguez-Serrano F, Peran M, Carrillo E, Velez C, Dominguez J, Gomez-Vidal JA, Campos J, Gallo MA, Espinosa $A$, Aranega $A$ : 5-fluorouracil derivatives induce differentiation mediated by tubulin and HLA class I modulation. Med Chem 2007, 3(3):233-239.

24. Ding XQ, Chen D, Wang AX, Li S, Chen Y, Wang J: Antitumor effects of hydroxycamptothecin-loaded poly[ethylene glycol]-poly [gamma-benzyl-L-glutamate] micelles against oral squamous cell carcinoma. Oncol Res 2007, 16(7):3/3-323.

25. Chen JH, Ling R, Yao Q, Wang L, Ma Z, Li Y, Wang Z, Xu H: Enhanced antitumor efficacy on hepatoma-bearing rats with adriamycin-loaded nanoparticles administered into hepatic artery. World I Gastroenterol 2004, I0(13): 1989-1991.

26. Shin IG, Kim SY, Lee YM, Cho CS, Sung YK: Methoxy poly(ethylene glycol)/epsilon-caprolactone amphiphilic block copolymeric micelle containing indomethacin. I. Preparation and characterization. J Control Release 1998, 5 I (I): I-I I.

27. Yoo HS, Park TG: Biodegradable polymeric micelles composed of doxorubicin conjugated PLGA-PEG block copolymer. J Control Release 200I, 70(I-2):63-70.

28. Deshpande MC, Garnett MC, Vamvakaki M, Bailey L, Armes SP, Stolnik $S$ : Influence of polymer architecture on the structure of complexes formed by PEG-tertiary amine methacrylate copolymers and phosphorothioate oligonucleotide. J Control Release 2002, 8 I (I-2): 185-199.

29. Zhang X, Pan SR, Hu HM, Wu GF, Feng M, Zhang W, Luo X: Poly(ethylene glycol)-block-polyethylenimine copolymers as carriers for gene delivery: Effects of PEG molecular weight and PEGylation degree. J Biomed Mater Res A 2007, 84(3):795-804.

30. Hu FQ, Hong $\mathrm{Y}$, Yuan H: Preparation and characterization of solid lipid nanoparticles containing peptide. Int J Pharm 2004, 273(I-2):29-35.

31. Xu Y, Du Y, Huang R, Gao L: Preparation and modification of $\mathbf{N}$ (2-hydroxyl) propyl-3-trimethyl ammonium chitosan chloride nanoparticle as a protein carrier. Biomaterials 2003, 24(27):5015-5022.

32. Lo CL, Lin KM, Hsiue GH: Preparation and characterization of intelligent core-shell nanoparticles based on poly(D,L-lactide)-g-poly(N-isopropyl acrylamide-co-methacrylic acid). J Control Release 2005, 104(3):477-488.

33. Torchilin VP: Drug targeting. Eur J Pharm Sci 2000, I I (SuppI 2):S8I-9I.

\section{Pre-publication history}

The pre-publication history for this paper can be accessed here:

http://www.biomedcentral.com/1471-2407/8/103/pre pub 